\title{
Silencing Aurora A leads to re-sensitization of breast cancer cells to Taxol through downregulation of SRC-mediated ERK and mTOR pathways
}

\author{
YAN LI ${ }^{1,2}$, WANQI ZHOU ${ }^{1,2}, \mathrm{KE} \mathrm{TANG}^{1,2}$, XIAOGUANG CHEN $^{1,2}$, ZHIQIANG FENG $^{3,4}$ and JINDONG CHEN $^{5}$ \\ ${ }^{1}$ State Key Laboratory of Bioactive Substances and Functions of Nature Medicines, ${ }^{2}$ Department of Pharmacology, \\ ${ }^{3}$ Beijing Key Laboratory of Active Substance Discovery and Drugability Evaluation, ${ }^{4}$ Department of Pharmacochemistry, \\ Institute of Materia Medica, Chinese Academy of Medical Sciences and Peking Union Medical College, Beijing 100050, \\ P.R. China; ${ }^{5}$ Department of Urology, University of Rochester Medical Center, Rochester, NY 14642, USA
}

Received March 3, 2017; Accepted July 31, 2017

DOI: $10.3892 /$ or.2017.5908

\begin{abstract}
While Taxol has been reported to improve the clinical survival of breast cancer patients, subsequently developed drug-resistance of the cancer cells limits its final efficacy and applications. Previous studies suggested that Aurora A is involved in the development of the Taxol-resistance of breast cancer. We established Taxol-resistant breast cancer MCF-7/T cells and xenograft models to explore the role of Aurora A in Taxol resistant ER-positive breast cancer. Compared with their parental MCF-7/C cells, the Taxol-resistant MCF-7/T cells exhibited enhanced colony formation, less cell death and higher invasive ability. The resistant cells presented overexpressed Aurora A, elevated phosphorylated SRC and upregulated Ras/ Raf/ERK and Akt/mTOR pathways. Silencing of Aurora A reduced the activity of SRC and downregulated the ERK and $\mathrm{Akt} / \mathrm{mTOR}$ pathways, which led to re-sensitization of the resistant MCF-7/T cells to Taxol in vitro. These results suggested that the activation of Aurora A and the subsequent upregulation of ERK and Akt through SRC induced Taxolresistance in breast cancer cells, and inhibiting Aurora A and the related SRC/EKT/Akt pathway could restore the sensitivity of breast cancer cells to Taxol. These results might shed light on the development of strategies to circumvent Taxol-related chemoresistance in breast cancer clinical practice.
\end{abstract}

Correspondence to: Dr Yan Li, State Key Laboratory of Bioactive Substances and Functions of Nature Medicines, Institute of Materia Medica, Chinese Academy of Medical Sciences and Peking Union Medical College, Beijing 100050, P.R. China

E-mail: lyhzytt@163.com

Professor Jindong Chen, Department of Urology, University of Rochester Medical Center, Rochester, NY 14642, USA

E-mail: jindong_chen@hotmail.com

Key words: Taxol, breast cancer, MAPK/ERK, Akt/mTOR, SRC, chemoresistance

\section{Introduction}

Breast cancer is one of the major causes of cancer-related death in women. Moreover, the incidence of breast cancer continues to rise in the world. In the treatment of breast cancer, Taxol/Paclitaxel is still regarded as one of the most effective drugs (1), which could prolong the survival of breast cancer patients in combination with other chemotherapy drugs (2). Unfortunately, continuous use of Taxol results in the acquired resistance of tumor cells to this drug. However, the molecular mechanisms of resistance to Taxol in breast cancer are not fully understood (3-5).

Aurora kinase has been observed highly expressed and amplified in breast cancer, which is related to survival and tumorigenesis (6,7). Moreover, overexpression of Aurora A induces chemoresistance in breast cancer cells and ovarian cancer cells (8). In the clinical trials for breast cancer, the expression level of Aurora A was related with the resistance of cancer cells to Taxol. The exact role of Aurora A in Taxolresistant breast cancer remains unclear. A previous report has shown that inhibition of Aurora A expression could result in the enhancement of Taxol-induced apoptosis in a variety of cancer cell lines, such as head and neck, esophageal and breast cancer cell lines $(9,10)$.

It has been established that Taxol inhibits signal pathways related to cell survival and growth, such as Ras/ERK and Akt kinase pathway (11-13). However, the Ras/ERK and Akt pathways were overexpressed in drug-resistant ovarian and colorectal cancers $(14,15)$. Furthermore, the overexpression of Akt and Ras/Raf/ERK pathways might be associated with the phosphorylation of SRC (16). As Aurora A was reported to promote proliferation and invasion through activation of the SRC and upregulate downstream pathways such as Ras/Raf/ERK and Akt/mTOR pathway $(17,18)$, we speculated that activated Aurora A might induce Taxol-resistance of breast cancer cells through SRC/ERK or SRC/Akt pathway. In the present study, by using our MCF-7/T cell and xenograft tumor models, we aimed to determine whether inhibition of Aurora A expression in Taxol-resistant breast cancer could downregulate the expression of SRC and downstream signaling pathways 
such as Ras/ERK and Akt and would suppress the tumor cell growth and restore cancer cell chemosensitivity to Taxol.

\section{Materials and methods}

Cell lines. MCF-7 cells were obtained from the Cell Center of CAMS \& PUMC (Beijing, China). The cells were maintained in Dulbecco's modified Eagle's medium (DMEM; Invitrogen, Carlsbad CA, USA) (19) supplemented with $10 \%$ fetal bovine serum (FBS; Invitrogen), $100 \mathrm{IU} / \mathrm{ml}$ penicillin and $100 \mu \mathrm{g} / \mathrm{ml}$ streptomycin (Invitrogen) in a humidified incubator containing $5 \% \mathrm{CO}_{2}$ at $37^{\circ} \mathrm{C}$.

Establishment of the Taxol-resistant MCF-7 model in vitro and in vivo. In the present study, MCF-7 resistant cell line MCF-7/T was developed through continued administration of sub-lethal concentrations of Taxol to the cells. A highly invasive and low colony was obtained from the MCF-7/T cells. In brief, MCF-7/T colonies were selected after 18 pulse drug treatments with Taxol. The majority of the cells were dead following $24 \mathrm{~h}$ of exposure to Taxol. The survived cells were then washed with $0.01 \mathrm{~mol} / 1$ phosphate-buffered saline (PBS) and cultured in Taxol growth medium. After 1-2 days, the dead cells were washed out with PBS and fresh Taxol medium was added. Once the cells reached $70-80 \%$ confluence, they were preserved for further study. The Taxol-resistant cell line was stabilized for $\sim 6$ months after treatment initiation and the resistant phenotype was developed. For the maintenance of Taxol-resistant cells, the MCF-7/T cells were grown in the presence of $0.001 \mu \mathrm{mol} / 1 \mathrm{Taxol}$. Prior to experimentation, MCF-7/T cells were maintained in a Taxol-free culture medium and subcultured for at least three generations. The drug-resistant characteristics of the MCF-7/T cells were tested using various concentrations of Taxol.

Taxol-resistant cells lose the resistant characteristics after injection into nude mice. To obtain an in vivo Taxol-resistant MCF-7 xenograft model (MCF-7/T) for studying resistance mechanisms frequently observed in a human therapeutic setting, MCF-7 cells were injected subcutaneously into the left flanks of the athymic nude mice (Balb/c-nu/nu females, 6-8 weeks old) which were purchased from Vital River Laboratory Animal Technology, Co., Ltd. (Beijing, China) and housed in the controlled environment at $25^{\circ} \mathrm{C}$ on a $12-\mathrm{h}$ light/dark cycle. Mice were maintained following the rules of the National Institute of Health Guide for the Care and Use of Laboratory Animals. Taxol-resistant MCF-7 xenograft tumors were achieved after ten passages of Taxol treatment. For each passage, mice were treated with $30.0 \mathrm{mg} / \mathrm{kg}$ Taxol $24 \mathrm{~h}$ before sacrifice. Then, xenograft tumors were collected and transplanted into the new athymic nude mice. After ten passages ( 12 months), drug-resistant characteristics of the xenografts were determined by the absence of tumor regression after treatment of Taxol.

Tissue culture from MCF-7 and Taxol-resistant MCF-7 xenograft model. Tumor tissues from a Taxol-resistant MCF-7 and a parent MCF-7 xenograft model were cut into small pieces with surgical scissors and minced with sterile razor blades until the explants size was $<1 \mathrm{~mm}^{3}$. The explants were transferred to flasks, trypsinized (Invitrogen) for $30 \mathrm{~min}$, covered with complete medium and incubated in an atmosphere of $5 \% \mathrm{CO}_{2}$ and $95 \%$ air at $37^{\circ} \mathrm{C}$. The medium was replaced after $48 \mathrm{~h}$.

Generation of the stable knockdown Aurora A in the MCF-7 and MCF-7/T cell. MCF-7 and MCF-7/T cell was seeded at a density of $1 \times 10^{5}$ cells/well in 6-well plates and incubated overnight or until cells reached $50 \%$ confluence. They were then transfected with either the AurA microRNAs, or control microRNA vector (BLOCK-iT ${ }^{\mathrm{TM}}$ Pol II miR RNAi Expression Vector kit with EmGFP, purchased from Invitrogen) through Lipofectamine 2000 (Invitrogen) following the manufacturer's protocol. The transfected cells were initially selected in DMEM medium containing $8 \mu \mathrm{g} / \mathrm{ml}$ Blasticidin $\mathrm{S} \mathrm{HCl}$ (Invitrogen). Selective pressure was maintained in a medium containing $8 \mu \mathrm{g} / \mathrm{ml}$ Blasticidin S $\mathrm{HCl}$ for two weeks. Clones with green fluorescence were collected for further culture in regular media. Then, cells were harvested for western blot analysis of Aurora A expression. Two stable transfected cell clones with AurA microRNAs, were designated as MCF-7/T/ AurA1 and MCF-7/T/AurA2. Stable transfected cells with control microRNA were designated as MCF-7/C and MCF-7/T/C (10). Since Aurora A-miRNA silencing constructs express GFP (BLOCK-iT ${ }^{\mathrm{TM}}$ Pol II miR RNAi Expression Vector kit with EmGFP) which would interfere with the flow cytometry (Annexin V-FITC) and TUNEL assay, we did not use flow cytometry (Annexin V-FITC) and TUNEL assay to detect apoptosis in the following experiments.

Analysis of cell proliferation and viability. MCF-7/C, MCF-7/T/C, MCF-7/T/AurA1 and MCF-7/T/AurA2 cells were seeded in 96-well plates in DMEM medium supplemented with $10 \%$ fetal bovine serum (FBS). The proliferation of the cells was monitored by CCK-8 assay every day for 14 days. MCF-7/C, MCF-7/T/C, MCF-7/T/AurA1 and MCF-7/T/AurA2 cells were seeded in 96-well plates in DMEM medium supplemented with $10 \%$ FBS. Cells were treated with dimethyl sulfoxide (DMSO) or Taxol for $72 \mathrm{~h}$ and then cell viability was measured with CCK-8 assay.

Colony formation assay. MCF-7/C, MCF-7/T/C, MCF-7/T/ AurA1 and MCF-7/T/AurA2 cells were trypsinized to singlecell suspensions. Then, cells were diluted in DMEM culture medium containing $10 \%$ FBS, and 300-600 cells were plated in each well of the 6-well plates. Cells were incubated with $5 \% \mathrm{CO}_{2}$ at $37^{\circ} \mathrm{C}$ for 14 days, and colonies were washed with PBS, fixed and stained with $0.005 \%$ crystal violet in methanol. Numbers of colonies were manually counted. Experiments were performed in triplicate and were repeated thrice.

Cell death and cell cycle analysis. MCF-7/C, MCF-7/T/C, MCF-7/T/AurA1 and MCF-7/T/AurA2 cells were treated with either Taxol, or 0.1\% DMSO for $72 \mathrm{~h}$, washed in PBS, and fixed with ice-cold $70 \%$ ethanol overnight. Cells were then suspended in PBS containing RNase A $(100 \mu \mathrm{g} / \mathrm{ml})$ and propidium iodide $(50 \mu \mathrm{g} / \mathrm{ml})$ and $0.1 \%$ Triton $\mathrm{X}-100$, and incubated in the dark for at least $1 \mathrm{~h}(20)$. Cell cycle profiles and death population were determined by flow cytometric (FCM) analysis. 
Table I. Effects of Taxol on MCF-7 tumors in athymic mice.

\begin{tabular}{|c|c|c|c|c|c|c|c|c|c|}
\hline & \multirow{2}{*}{$\begin{array}{c}\text { Dose } \\
(\mathrm{mg} / \mathrm{kg})\end{array}$} & \multirow{2}{*}{$\begin{array}{c}\text { No. of } \\
\text { animals (n) }\end{array}$} & \multicolumn{2}{|c|}{ Body weight (g) } & \multicolumn{3}{|c|}{ Tumor size } & \multicolumn{2}{|c|}{ Tumor weight } \\
\hline & & & Start & End & Volume $\left(\mathrm{mm}^{3}\right)$ & RTV & $\mathrm{T} / \mathrm{C}(\%)$ & (g) & Inhibition (\%) \\
\hline Control & & $5 / 5$ & $22.6 \pm 0.6$ & $26.0 \pm 1.2$ & $1163.8 \pm 503.2$ & $5.06 \pm 2.46$ & & $1.02 \pm 0.46$ & \\
\hline Taxol & 5.0 & $5 / 5$ & $21.0 \pm 1.6$ & $22.8 \pm 2.3$ & $68.3 \pm 32.5^{\mathrm{a}}$ & $0.34 \pm 0.22^{\mathrm{a}}$ & 6.75 & $0.04 \pm 0.02^{\mathrm{a}}$ & 96.36 \\
\hline
\end{tabular}

${ }^{\mathrm{a}} \mathrm{P}<0.01$ vs. control. $\mathrm{T} / \mathrm{C}(\%)=\mathrm{T}_{\mathrm{RTV}} / \mathrm{C}_{\mathrm{RTV}} \mathrm{x} 100 ; \mathrm{RTV}$, relative tumor volume.

Table II. Effects of Taxol on MCF-7/T tumors in athymic mice.

\begin{tabular}{|c|c|c|c|c|c|c|c|c|c|}
\hline & \multirow{2}{*}{$\begin{array}{c}\text { Dose } \\
(\mathrm{mg} / \mathrm{kg})\end{array}$} & \multirow{2}{*}{$\begin{array}{c}\text { No. of } \\
\text { animals (n) }\end{array}$} & \multicolumn{2}{|c|}{ Body weight (g) } & \multicolumn{3}{|c|}{ Tumor size } & \multicolumn{2}{|c|}{ Tumor weight } \\
\hline & & & Start & End & Volume $\left(\mathrm{mm}^{3}\right)$ & RTV & $\mathrm{T} / \mathrm{C}(\%)$ & (g) & Inhibition (\%) \\
\hline Control & & $5 / 5$ & $18.0 \pm 1.4$ & $18.6 \pm 2.4$ & $1373.5 \pm 363.1$ & $12.19 \pm 2.78$ & & $1.26 \pm 0.24$ & \\
\hline Taxol & 5.0 & $5 / 4$ & $16.8 \pm 1.9$ & $17.5 \pm 2.1$ & $1871.0 \pm 981.5$ & $12.59 \pm 3.17$ & 103.3 & $1.36 \pm 0.48$ & - \\
\hline
\end{tabular}

$\mathrm{T} / \mathrm{C}(\%)=\mathrm{T}_{\mathrm{RTV}} / \mathrm{C}_{\mathrm{RTV}} \times 100 ; \mathrm{RTV}$, relative tumor volume.

In vitro invasion assay. Invasion was determined using a variation of the Boyden chamber assay as previously described (21). Briefly, cells were trypsinized and counted; next, $1 \times 10^{6}$ cells (MCF-7/C, MCF-7/T/C, MCF-7/T/AurA1 and MCF-7/T/ AurA2) and cells cultured from tumor tissue (MCF-7, MCF-7/T xenograft model) suspended in $200 \mu \mathrm{l}$ of DMEM containing $0.1 \%$ BSA. The cells were seeded into the upper compartment (Costar, Costar, Cambridge, MA, USA) coated polycarbonate filter with a pore size of $8.0 \mu \mathrm{m}$ in a 24-well plate. Each polycarbonate filter was coated with $10 \mu \mathrm{l}$ of $0.5 \%$ Matrigel before the addition of cells. DMEM medium $(500 \mu \mathrm{l})$ containing $10 \%$ FBS was added to the lower compartment as a chemoattractant. After $18 \mathrm{~h}$ of incubation at $37^{\circ} \mathrm{C}$ with $5 \%$ $\mathrm{CO}_{2}$, the cells on the lowerside of the filter were fixed to the membrane using methanol for $10 \mathrm{~min}$. Filters were stained with hematoxylin and eosin $(\mathrm{H} \& \mathrm{E})$ at room temperature. Cells in the upper compartment were removed using a cotton swab, leaving only the cells on the underside of the filter, representing those cells that had successfully invaded across the Matrigel-coated filter. The chambers were then photographed to compare the amount of invasive cells on the underside of the membrane. Five visual fields were photographed in every membrane and nuclear-stained cells were manually counted. All samples were run in triplicate.

Cell lysates and western blot analysis. Lysates (from MCF-7/C, MCF-7/T/C, MCF-7/T/AurA1 and MCF-7/T/AurA2 cells) were prepared following the method previously described. Portion of three randomly selected tumors from each group (MCF-7 and MCF-7/T) were homogenized for lysate preparation as previously described (22). For western blot analysis, samples were transferred to a nitrocellulose membrane by semi-wet electrophoresis (Invitrogen), and incubated with primary antibodies (rabbit anti-Aurora A, rabbit anti-phosphorylated Aurora A (Thr288), rabbit anti-phosphorylated SRC (Tyr416), rabbit anti-SRC, rabbit anti-phosphorylated Akt (Ser473), rabbit anti-Akt, rabbit anti-phosphorylated mTOR, rabbit anti-mTOR, rabbit anti-phosphorylated p70s6 (Thr389), rabbit anti-phosphorylated c-Raf (Ser259), rabbit anti-c-Raf, rabbit anti-phosphorylated MEK, rabbit anti-MEK, rabbit antiphosphorylated p-ERK, rabbit anti-ERK, mouse anti-cyclin B, mouse anti-cdc2, rabbit anti-Bcl-2, rabbit anti-c-caspase 3, rabbit anti-c-PARP, rabbit anti-MMP9, rabbit anti-MMP2 and rabbit anti- $\beta$-actin) overnight at $4^{\circ} \mathrm{C}$, detected with horseradish peroxidase-conjugated anti-rabbit or anti-mouse IgG (Santa Cruz Biotechnology, Santa Cruz, CA, USA) and developed using an ECL Western blot detection and analysis system (Applygen Technologies, Inc., Beijing, China). Membranes were tested for equal loading by probing for $\beta$-actin.

ELISA assay. Lysates (portion of three randomly selected tumors from MCF-7 and MCF-7/T) were mixed and homogenized for lysate preparation as previously described (22). For ELISA assay, the protocol of Phospho-Aurora A (Thr288) sandwich ELISA kit (\#7114; Cell Signaling Technology, Danvers, MA, USA) was followed.

Statistical analysis. All values were expressed as mean \pm SD. Values were compared using the Student's t-test. $\mathrm{P}<0.05$ was considered significant.

\section{Results}

Activation of Aurora A and SRC in Taxol-resistant MCF-7 model $(M C F-7 / T)$ in vitro and in vivo. To examine whether Aurora A activation was related to the resistance of breast cancer to Taxol, we established a Taxol-resistant breast cancer cell clone MCF-7/T in vitro and developed two xenograft tumor models, the Taxol-resistant MCF-7/T and the Taxolsensitive parental MCF-7. When a Taxol dose of $5.0 \mathrm{mg} / \mathrm{kg}$ was 
A
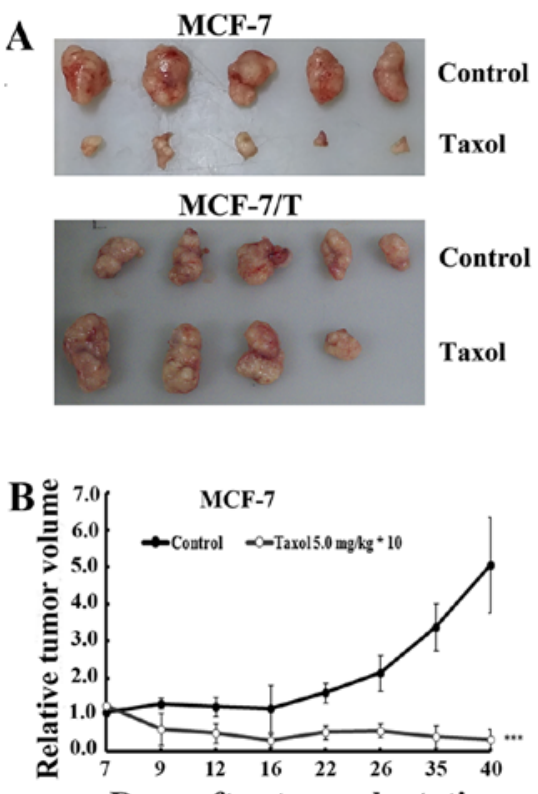

Days after transplantation

C

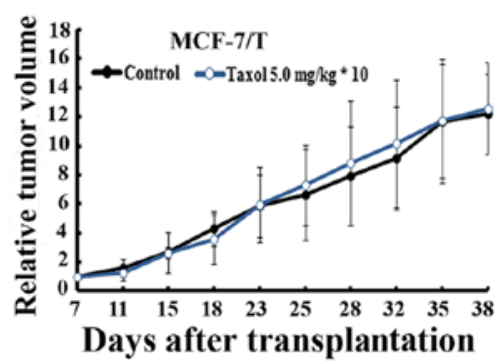

$\mathbf{E}$
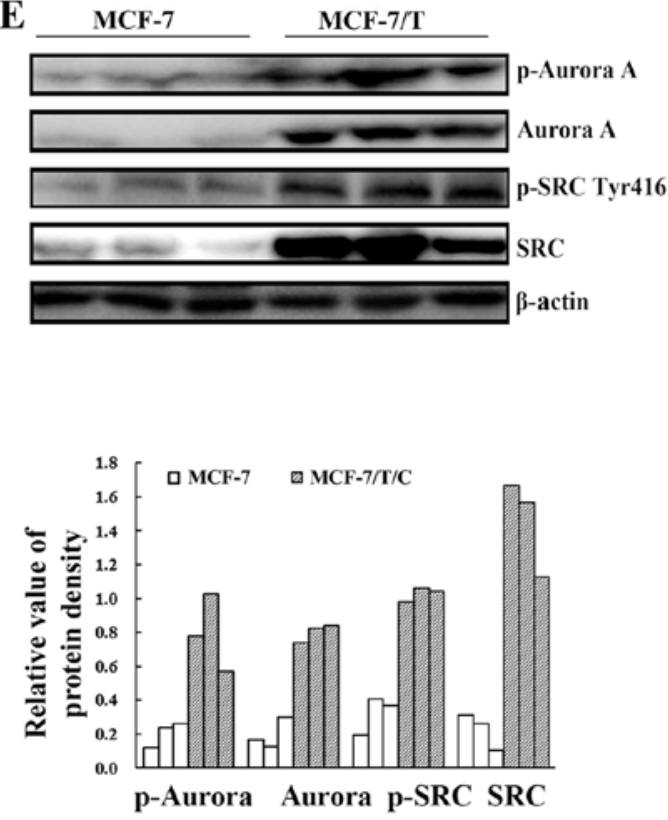

F

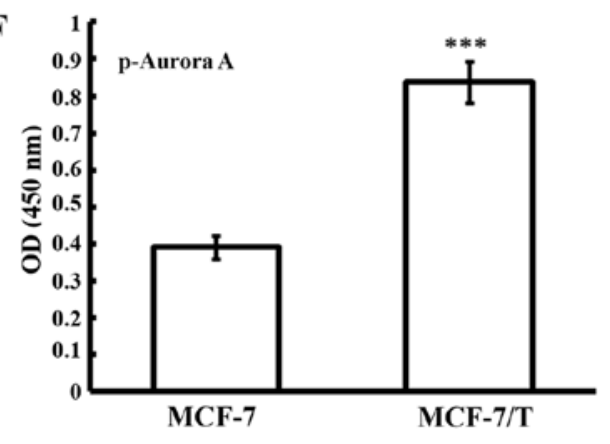

D

MCF-7/C MCF-7/T/C
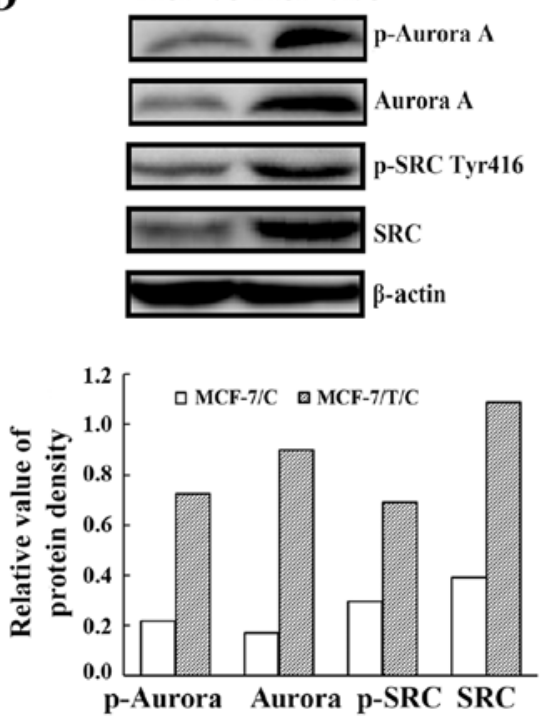

Figure 1. Overexpression of the Aurora A in Taxol-resistant breast cancer in vitro and in vivo. (A) Taxol-treated MCF-7 and MCF-7/T xenograft tumors with controls. (B and C) Establishment of Taxol-resistant MCF-7 xenograft model. Tumor resistance was achieved after ten passages of Taxol treatment in vivo through xenograft tumorigenesis in the flanks of athymic nude mice. In each passage, the nude mice $(\mathrm{n}=10)$ were treated with $30.0 \mathrm{mg} / \mathrm{kg} 24 \mathrm{~h}$ before being euthanized. Resistance was characterized by the absence of tumor regression $\left({ }^{* * *} \mathrm{P}<0.001\right.$, Taxol-treatment group vs. the MCF-7 control group). (D) Western blot analysis of Aurora A and SRC expression in MCF-7/C and MCF-7/T/C cells. Cell lysates prepared from MCF-7/C and MCF-7/T/C were subjected to SDS-PAGE and blotted with specific antibody. The expression level of p-Aurora A, Aurora A, p-SRC and SRC were higher in the Taxol-resistant MCF-7/T/C cells compared to the MCF-7/C control. (E) Western blot analysis of Aurora A and SRC expression in the xenografted tumors (3 samples/group). A higher expression of p-Aurora A, Aurora A, p-SRC and SRC were observed in the Taxol-resistant xenograft group than that in the parent MCF-7 tumors. (F) p-Aurora A expression in MCF-7 and MCF-7/T xenograft tumors by ELISA assay. Tumor proteins extracted from MCF-7 and MCF-7/T groups were subjected to ELISA assay. The expression of p-Aurora A was higher in MCF-7/T tumors than that in MCF-7. 
A
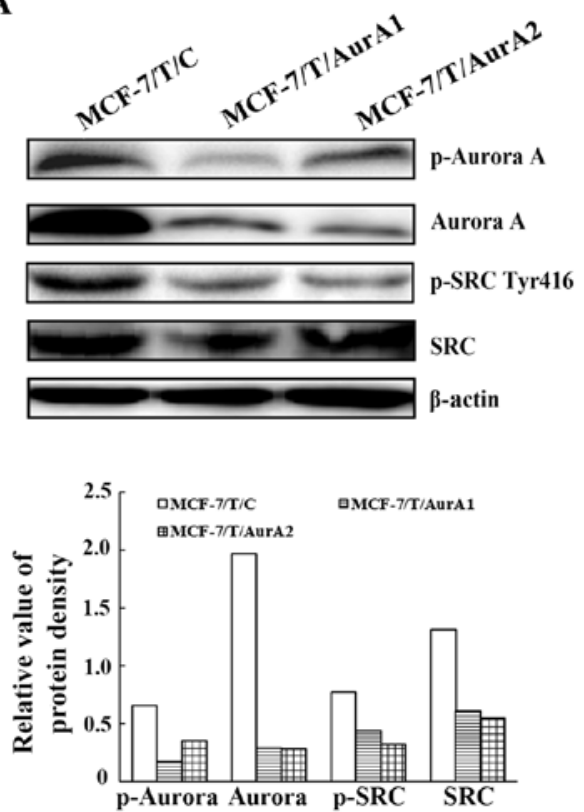

Ba

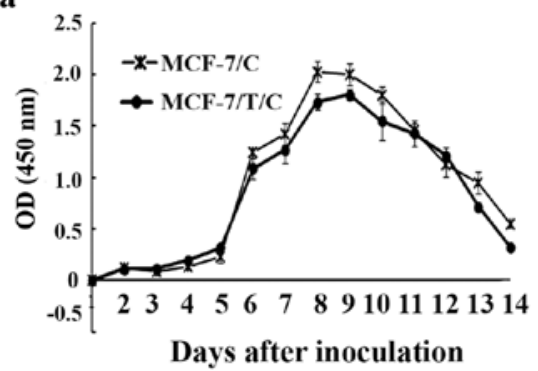

Bb

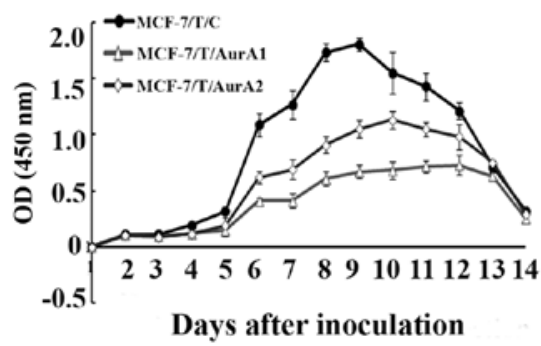

Ca
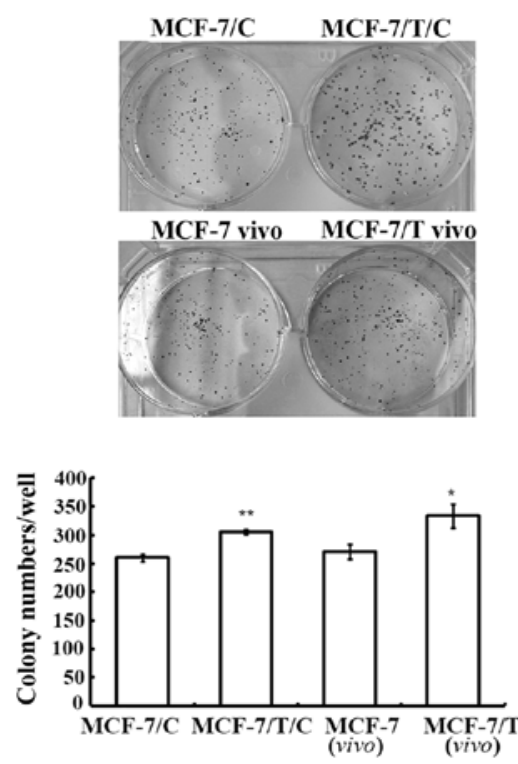

Cb
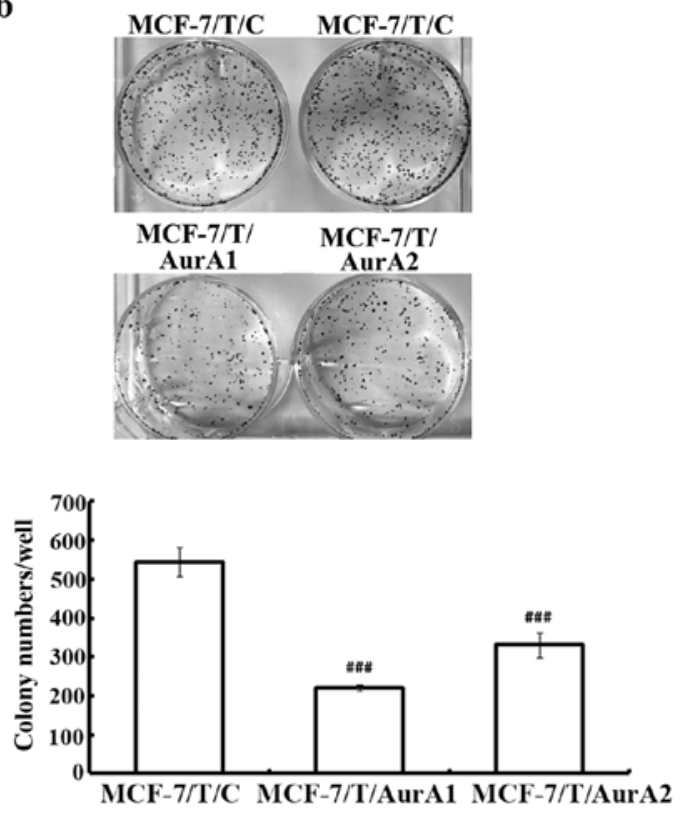

Figure 2. Knockdown of Aurora A led to anti-proliferation in MCF-7/T cells. (A) Western analysis showed the expression of Aurora A, SRC, p-Aurora A, and p-SRC in silenced tumor cells (MCF-7/T/AurA1 and MCF-7/T/AurA2, transfected with Aurora A microRNA1 and Aurora A microRNA2, respectively) significantly reduced compared to the MCF-7/T cells (MCF-7/T/C) transfected with control microRNA. (Ba and Bb) There was no apparent growth difference between the Taxol-resistant MCF-7/T/C cells and the MCF-7/C parent cells after being transfected with the control microRNA. (Ca and Cb) The colony formation ability of the MCF-7 cells was lower than the Taxol-resistant MCF-7/T cells (Ca), whereas, the colony formation ability of Aurora A microRNA silenced cells (MCF-7/T/AurA1 and MCF-7/T/AurA2) significantly decreased (Cb). Error bars represented standard deviation. ${ }^{*} \mathrm{P}<0.05$, ${ }^{* * *} \mathrm{P}<0.01$ indicated statistically significant divergence from the parent cells $(\mathrm{MCF}-7 / \mathrm{C}){ }^{. \# \#} \mathrm{P}<0.001$ indicated statistically significant divergence from the negative control cells $(\mathrm{MCF}-7 / \mathrm{T} / \mathrm{C})$.

adopted, the parental Taxol-sensitive MCF-7 tumors exhibited significant growth inhibition while the MCF-7/T xenografts presented resistance to Taxol. The relative tumor volume (RTV) of MCF-7 was 5.06 \pm 2.46 (control) vs. 0.34 \pm 0.22 (Taxol $5.0 \mathrm{mg} / \mathrm{kg}$ ) (Table I and Fig. 1A and B), whereas the RTV of MCF-7/T was $12.19 \pm 2.78$ (control) vs. 12.59 \pm 3.17 (Taxol $5.0 \mathrm{mg} / \mathrm{kg}$ ) (Table II and Fig. 1A and C). The results indicated that MCF-7/T tumors had developed resistance to Taxol in vivo and was suitable for further study.
We further examined the expression of Aurora $\mathrm{A}$ in MCF-7/C and MCF-7/T/C cell lines, as well as MCF-7 and MCF-7/T xenograft tumors. Western blot analysis revealed that both p-Aurora A and Aurora A were highly expressed in Taxol-resistant MCF-7/T cells and xenograft tumors analyzed (Fig. 1D and E). ELISA further confirmed that the Aurora A was activated in MCF-7/T xenograft tumors (Fig. 1F). Given previous report (23) suggested that Aurora A might function through phosphorylation of SRC at tyrosine 416, we herein 

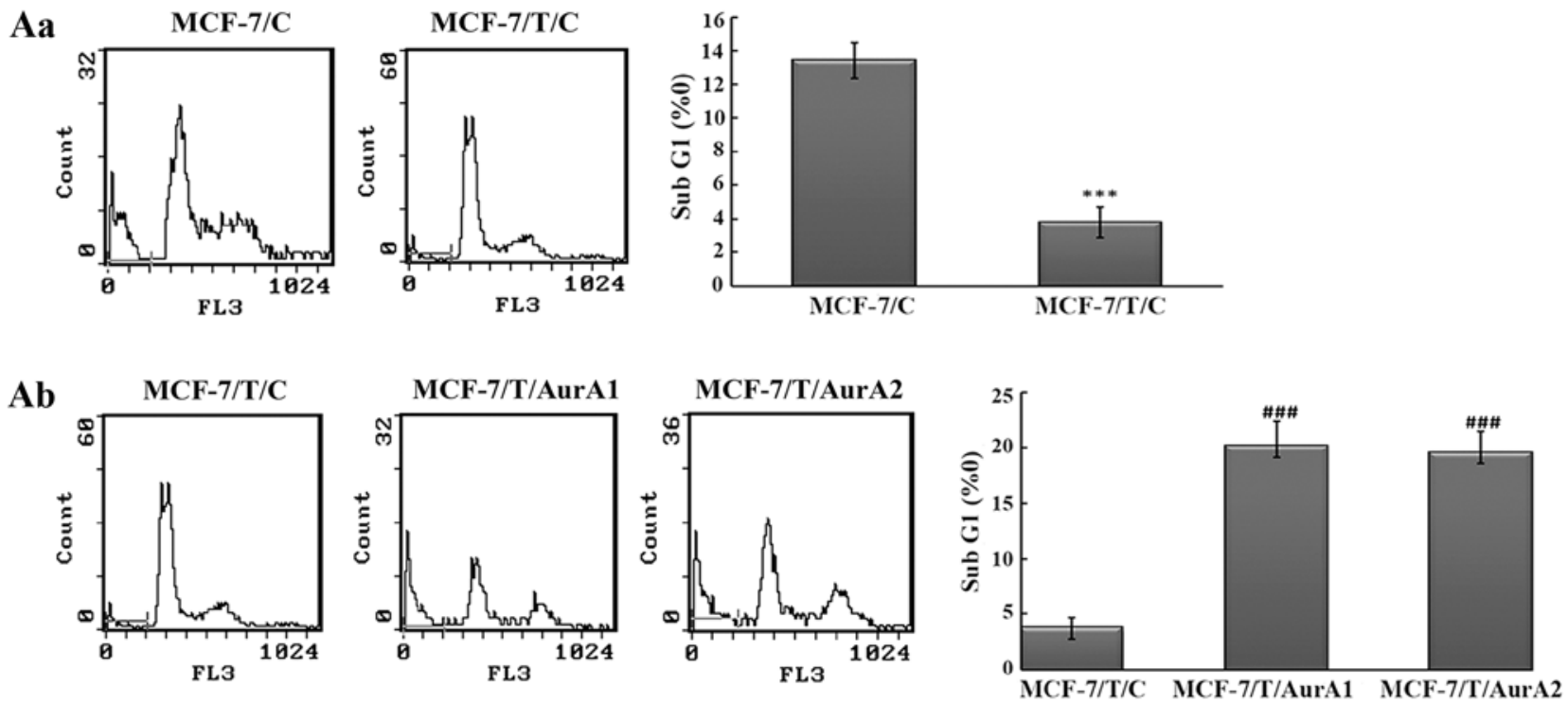

Ba
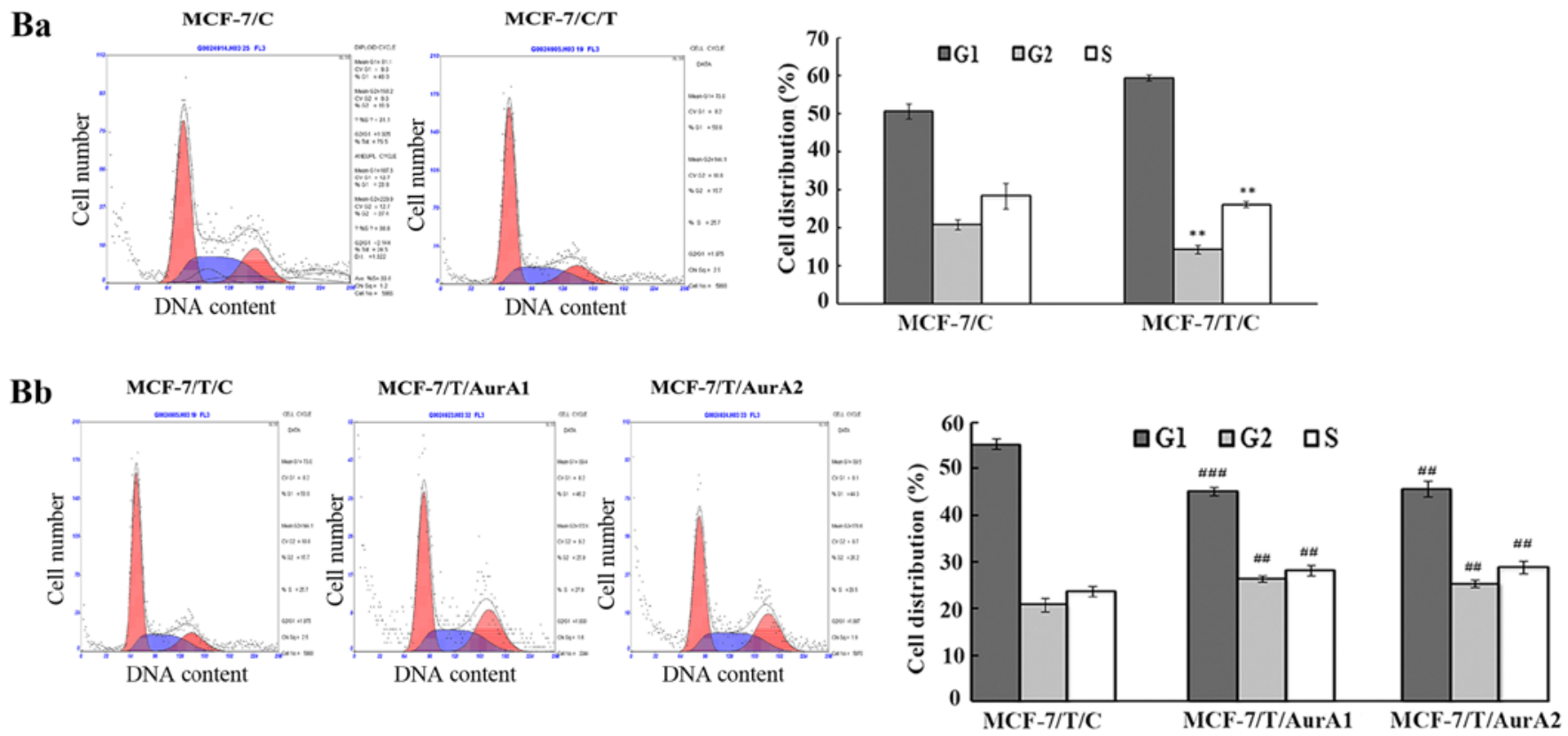

Figure 3. Knockdown of Aurora A causes cell cycle arrest plus cell death in MCF-7/T cells. (Aa and Ab) Aurora A microRNAs induced cell death. MCF-7 cells showed higher death than the Taxol-resistant MCF-7/T cells (MCF-7/T/C) when both of them were treated with control microRNAs (Aa). In contrast, MCF-7/T cells displayed higher death after treatment with the Aurora A microRNAs (MCF-7/T/AurA1 and MCF-7/T/AurA2) compared to the cells treated with control microRNA (MCF-7/T/C) (Ab). The treatment experiments in Aa and Ab were performed simultaneously, thus, the same MCF-7/C/T result was represented in both of $\mathrm{Aa}$ and $\mathrm{Ab}$ for comparison purpose. Cells were cultured for $72 \mathrm{~h}$, stained with propidium iodide (PI) and analyzed by FCM. Error bars represent standard deviation. ${ }^{* * *} \mathrm{P}<0.001$ indicated statistically significant divergence from the parent cells MCF-7/C; ${ }^{* \# \#} \mathrm{P}<0.001$ indicated statistically significant divergence from the negative control cells (MCF-7/T/C). (Ba and Bb) Aurora A microRNAs knockdown mediated cell cycle arrest in G2/M phase in the Taxol-resistant MCF-7/T cells. Cells were cultured for $72 \mathrm{~h}$, and then stained with propidium iodide (PI) and analyzed by FCM. Error bars represent standard deviation. ${ }^{* *} \mathrm{P}<0.01$ indicated statistically significant divergence from the parent cells $\mathrm{MCF}-7 / \mathrm{C} ;{ }^{\# /} \mathrm{P}<0.01,{ }^{\# \# \#} \mathrm{P}<0.001$ indicated statistically significant divergence from the negative control cells.

validated that the level of $\mathrm{p}$-SRC and SRC was upregulated in MCF-7/T cells and tumors as well (Fig. 1D and E). These results implied that the activation of Aurora A and SRC might be linked to the resistance of the breast cancer to Taxol.

Specific silencing of Aurora A in MCF-7/T cells led to downregulation of SRC phosphorylation. To further determine the partnership between Aurora A and SRC in resistance to Taxol, MCF-7/T cells were transfected with either vector-containing human-specific Aurora A microRNAs or a vector-containing control microRNA. Two Aurora A microRNA stable-expressing clones (named as MCF-7/T/AurA1 and MCF-7/T/AurA2) were chosen for subsequent experiments. Our western blot analyses displayed that Aurora A as well as p-Aurora A were downregulated significantly in MCF-7/T/AurA1 and MCF-7/T/ AurA2 cells compared to control microRNA-expressing cells (MCF-7/T/C) (Fig. 2A). Concurrently, SRC phosphorylation significantly decreased while the total of SRC was not influ- 

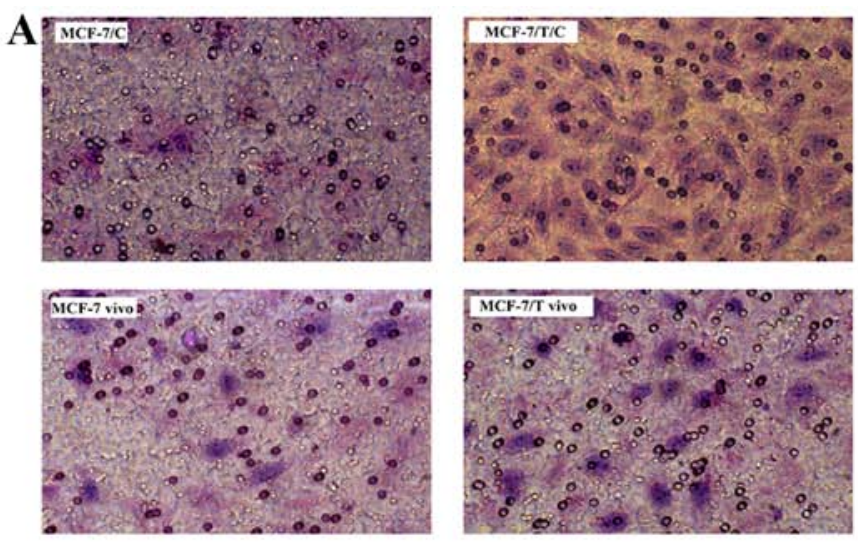

B
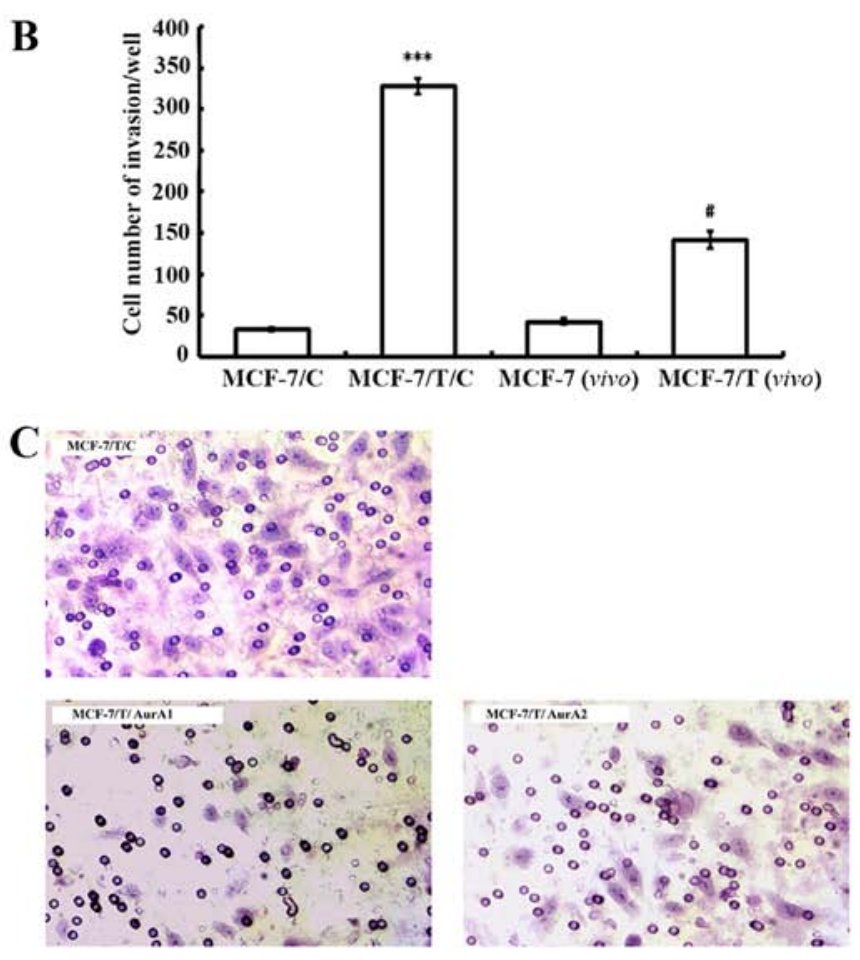

D

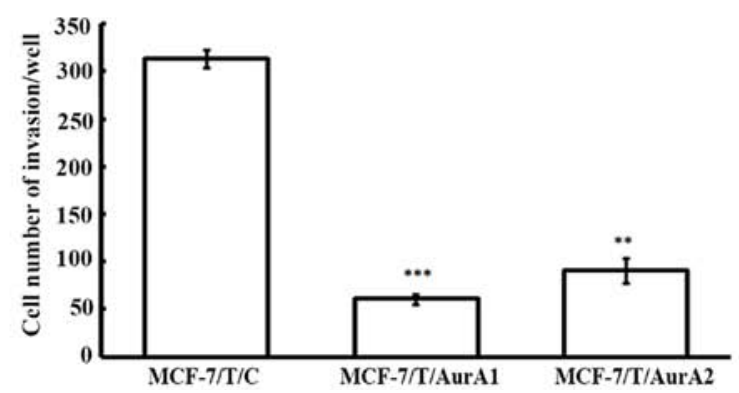

Figure 4. Aurora A silencing leads to reduced invasion in the MCF-7/T cells. (A and $\mathrm{B}$ ) $\mathrm{MCF}-7 / \mathrm{T}$ cells showed higher invasion compared to the parent MCF-7/C cells in both regular MCF-7 cell lines and xenograft-originated MCF-7 cells [MCF-7(vivo) and MCF-7/T(vivo)]. Error bars represent standard deviation. ${ }^{* * *} \mathrm{P}<0.001$ indicated statistically significant divergence from the parent cells $\mathrm{MCF}-7 / \mathrm{C}$; ${ }^{\#} \mathrm{P}<0.05$ indicated statistically significant divergence from the parent cells MCF-7/C(vivo). (C and D) Aurora A microRNA-treated MCF-7/T cells presented lower invasion compared to the control microRNAtreated ones. Error bars represented the standard deviation and an asterisk indicates statistically significant divergence from the negative control clones; ${ }^{* *} \mathrm{P}<0.01,{ }^{* * * *} \mathrm{P}<0.001$.

enced (Fig. 2A). These data indicated that SRC activity might be regulated by Aurora A in MCF-7/T cells.
Knockdown of Aurora A inhibits MCF-7/T cell proliferation. To explore whether high expression of Aurora A contributes to cell proliferation, the MCF-7/T/AurA1 and MCF-7/T/AurA2 cells were monitored in vitro by CCK- 8 assay for 14 days. While there was no significant cell viability difference between MCF-7/C and MCF-7/T/C (Fig. 2Ba), the MCF-7/T cell proliferation significantly decreased upon silencing of Aurora A (MCF-7/T/AurA1 and MCF-7/T/AurA2) in a timedependent manner compared with the negative MCF-7/T/C controls, and the highest inhibitory rates were 65.1 and $47.5 \%$ (Fig. 2Bb) on the 8th day, respectively. In addition, our colony formation assay indicated that the number of colonies in the $\mathrm{MCF}-7 / \mathrm{T} / \mathrm{C}$ cells was higher than in $\mathrm{MCF}-7 / \mathrm{C}$ cells (average colony number, $305.7 \pm 4.0$ and $260.3 \pm 6.4$, respectively) (Fig. 2Ca), whereas the number of colonies in the MCF-7/T/ AurA1 and MCF-7/T/AurA2 cells (average colony number, $221.3 \pm 31.9$ and $330.7 \pm 10.07$, respectively) were significantly decreased compared to the $\mathrm{MCF}-7 / \mathrm{T} / \mathrm{C}$ control cells (average

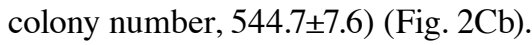

Silencing of Aurora A induces MCF-7/T cells death. To study the impact of Aurora A expression on cell death in Taxol resistant breast cancer cells, we examined the percentage of SubG1 phase in MCF-7/T sublines (MCF-7/T/C, MCF-7/T/AurA1 and MCF-7/T/AurA2) by FCM. The results revealed, that when both MCF-7/C and MCF-7/T/C cells were cultured for $72 \mathrm{~h}$, the percentage of $\mathrm{MCF}-7 / \mathrm{T} / \mathrm{C}$ cells in the SubG1 $(3.8 \pm 0.9 \%)$ was lower than the parental MCF-7/C population $(13.4 \pm 1.1 \%)$ (Fig. 3Aa). Moreover, in the silenced MCF-7/T/AurA1 and MCF-7/T/AurA2 cells, the SubG1 phase percentage was increased by $20.2 \pm 2.3$ and $19.5 \pm 2.0 \%$ compared with control MCF-7/T/C cells (3.8 $\pm 0.9 \%)$ (Fig. 3Ab). These results demonstrated that downregulation of Aurora A could induce $\mathrm{MCF}-7 / \mathrm{T}$ cell death.

Knockdown of Aurora A causes G2/M arrest in MCF-7/T cells. As Aurora A could exert positive effects on the cell cycle in several cell lines in a dose-dependent manner, we further examined whether knockdown of Aurora A would lead to cell cycle arrest in MCF-7/T. The results showed that the percentage of G2/M phase in the Taxol-resistant MCF-7/T/C cells was lower than that in the $\mathrm{MCF}-7 / \mathrm{C}$ control cells. The percentages of the $\mathrm{G} 2 / \mathrm{M}$ cells were $14.3 \pm 1.3 \%$ for MCF-7/C and $20.9 \pm 1.3$ for $\mathrm{MCF}-7 / \mathrm{T} / \mathrm{C}$ (Fig. 3Ba). We observed that inhibition of Aurora A by microRNAs led to cell G2/M-phase accumulation (Fig. 3Bb) and G1-phase decrease in the Taxol-resistant cells. The cell percentages of $\mathrm{G} 2 / \mathrm{M}$ phase in MCF-7/T/AurA1 and MCF-7/T/AurA2 cells increased by $26.4 \pm 0.8$ and $25.4 \pm 0.7 \%$, respectively, compared with $20.8 \pm 1.5 \%$ in $\mathrm{MCF}-7 / \mathrm{T} / \mathrm{C}$ control cells (Fig. 3Bb).

Silencing of Aurora A inhibits MCF-7/T cell invasion in vitro. To determine the effect of elevated Aurora A on MCF-7/T invasive capacity, we further conducted invasion assay. The MCF-7/T sublines and MCF-7/C control cells were allowed to invade through a membrane coated with Matrigel, toward a chemo-attractant (10\% FBS) for $18 \mathrm{~h}$. While only $32.5 \pm 2.1 /$ well MCF-7/C cells exhibited invasion, there were 327.5 \pm 9.2 / well $\mathrm{MCF}-7 / \mathrm{T} / \mathrm{C}$ cells invaded through the membrane, indicating $\mathrm{MCF}-7 / \mathrm{T} / \mathrm{C}$ cells presented an enhanced inva- 
Aa
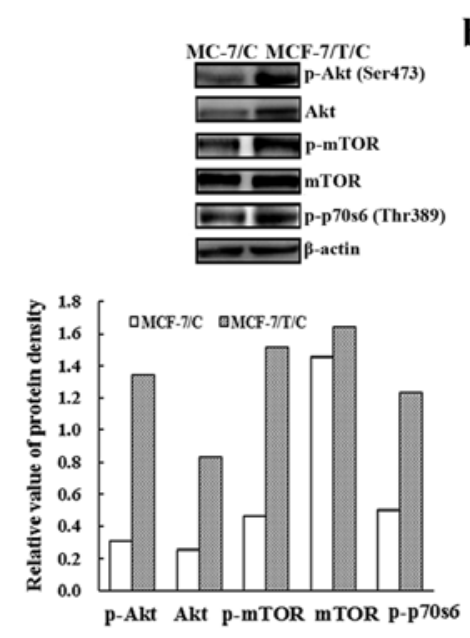

b

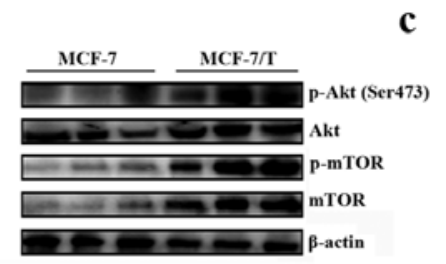

c

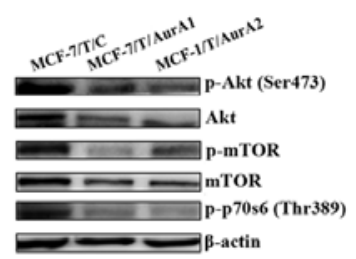

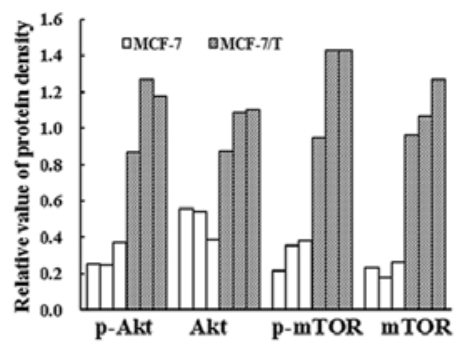

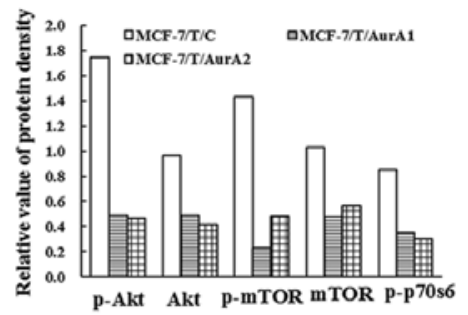

Ba

Bb

Bc
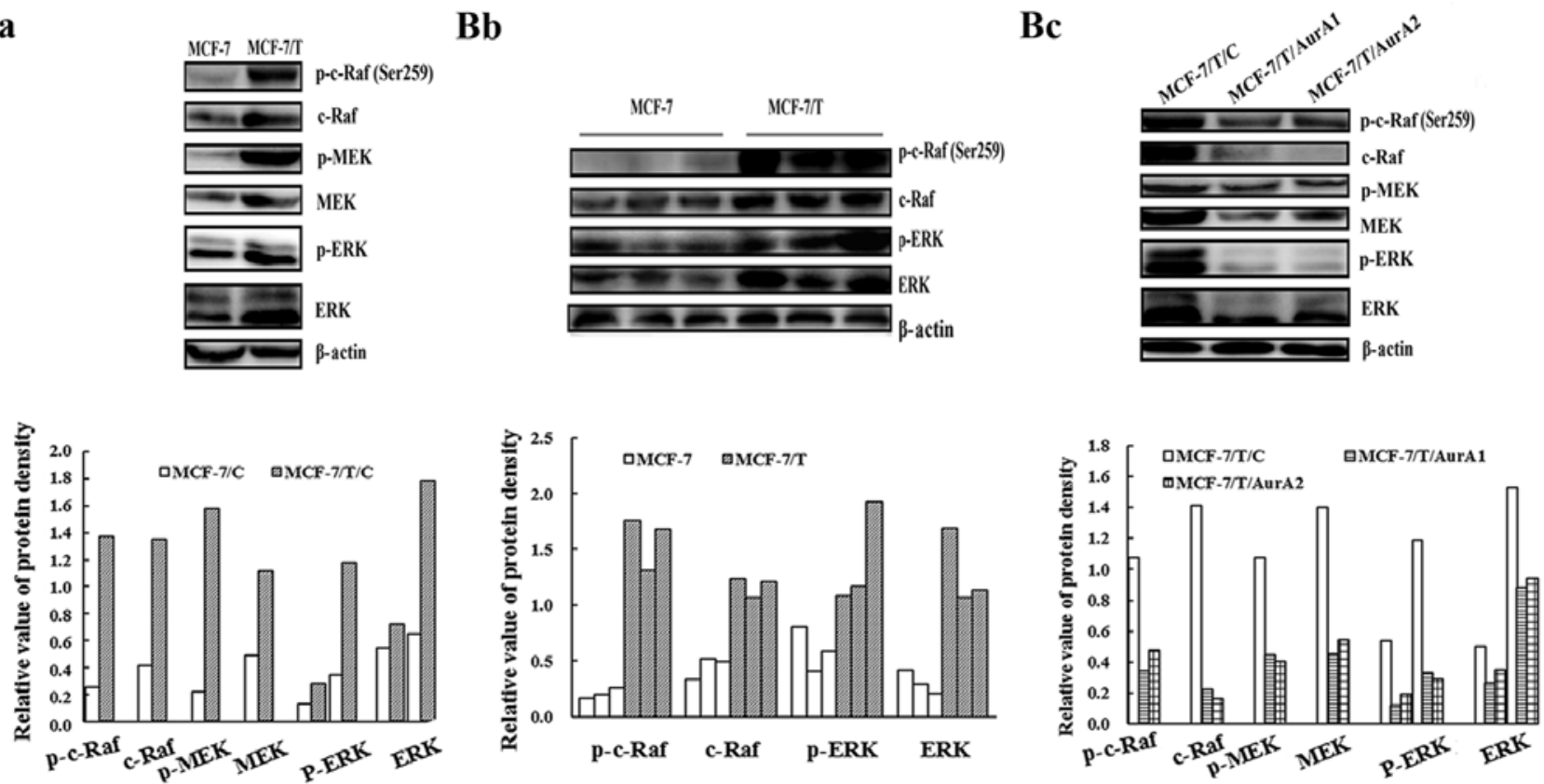

Figure 5. Aurora A silencing downregulates pathways related to proliferation, invasion and cell cycle, and causes cell death in MCF-7/T cells in vitro and in vivo. (Aa-Ac) Western blot analysis indicated that the Akt signaling pathway was activated in the MCF-7/T/C cells (Aa) and the MCF-7/T tumors (Ab). Whereas, it was downregulated upon Aurora A silencing (Ac); (Ba-Bc) while the downstream c-Raf signaling pathway displayed high activity in the MCF-7/T/C cells (Ba) and the MCF-7/T tumors (Bb), it was inhibited after Aurora A knockdown (Bc);

sive ability compared with MCF-7/C cells (Fig. 4A and B). Moreover, the xenograft-originated Taxol-resistant MCF-7 cells [MCF-7/T(vivo)] were more invasive than the parent xenograft-originated MCF-7 cells [MCF-7(vivo)], [MCF-7/

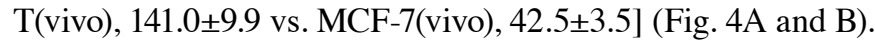
After knockdown of Aurora A by microRNAs, the invaded cells decreased by $80.7 \%$ (MCF-7/T/AurA1, 60.5 $\pm 4.9 /$ well) and $71.0 \%$ (MCF-7/T/AurA2, 91.0 $\pm 12.7 /$ well) compared to the untreated control MCF-7/T/C cells $(313.5 \pm 9.20 /$ well) (Fig. 4C and D), suggesting that inhibition of Aurora could considerably reduce the invasive ability of MCF-7/T cells.

Suppression of Aurora A downregulates the RaflERK and Akt pathway in MCF-7/T cells. Aurora A interacts with several proteins related to proliferation, survival, cell cycle, apoptosis, and invasive signaling pathways such as Raf/ERK and Akt (24-26). We examined whether knockdown of Aurora A would downregulate the ERK and Akt pathways in the MCF-7 and MCF-7/T subline cells and xenograft tumors. As shown in Fig. 5Aa, 5Ab, 5Ba and 5Bb, Akt, mTOR, p70s6, c-Raf, MEK and ERK were highly phosphorylated in the Taxol resistant MCF-7 cells and tumors. Whereas, the phosphorylation and basal levels of these proteins were remarkably reduced in MCF-7/T/AurA1 and MCF-7/T/AurA2 cells compared with the negative control MCF-7/T/C (Fig. 5Ac and 5Bc), indicating inhibition of Aurora A significantly downregulated the Ras/Raf/ERK and Akt pathway.

Since cyclin B/cdc2 complex regulates cell cycle (27), we herein found that the cyclin B and cdc2 were overexpressed in MCF-7/T cells and xenograft tumors (Fig. $5 \mathrm{Ca}$ and $5 \mathrm{Cb}$ ). Nevertheless, the expressions of cyclin B and cdc2 were decreased in the MCF-7/T/AurA1 and MCF-7/T/AurA2 cells though the decrease of cyclin $\mathrm{B}$ was not significant in the MCF-7/T/AurA1 cells (Fig. 5Cc), suggesting that Aurora A 
$\mathrm{Ca}$

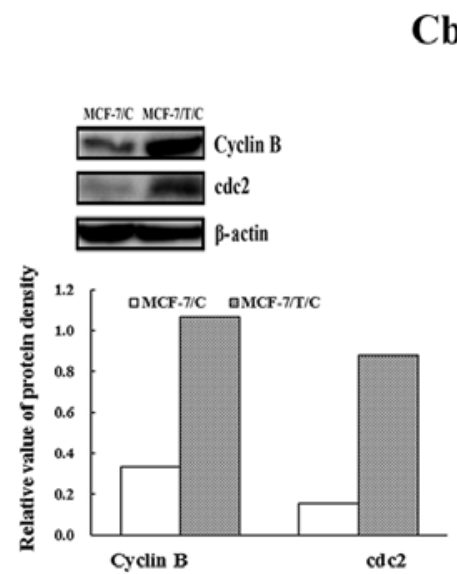

Da

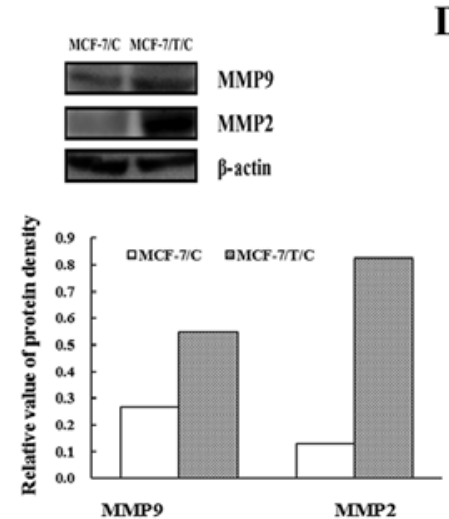

$\mathrm{Cb}$
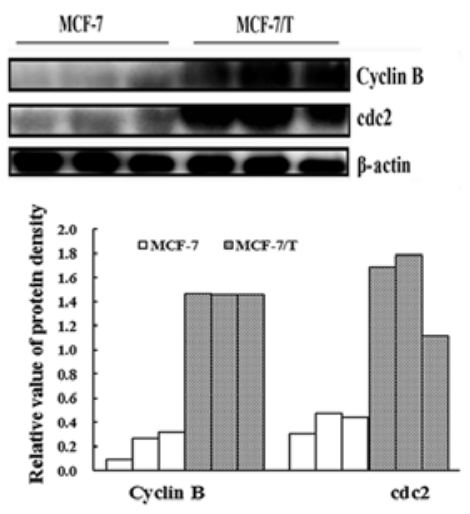

Db
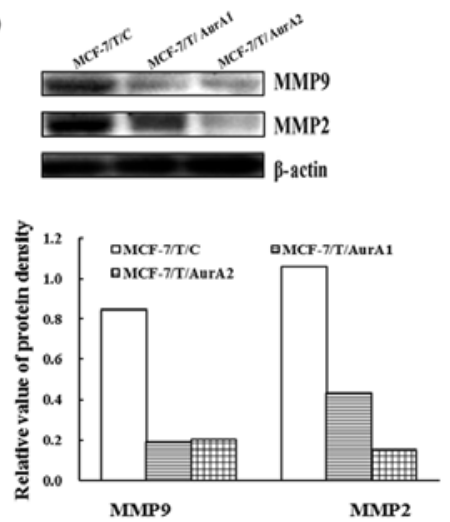

Ce

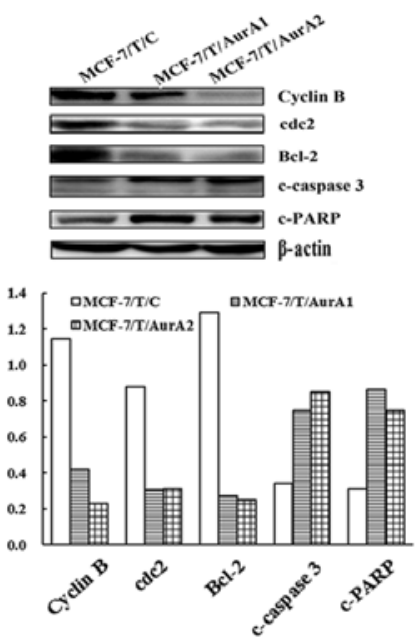

Figure 5. Continued. (Ca-Cc) The expression of cell cycle signaling pathways in MCF-7/T/C cells (Ca) and MCF-7/T tumors (Cb), and they were suppressed and apoptosis was induced in MCF-7/T cells after Aurora A silencing (Cc) (here the same western blot membrane used in Fig. 1D was adopted for Fig. 5Ca immunoblotting); ( $\mathrm{Da}$ and $\mathrm{Db}$ ) western blot analysis showed that the metastasis related proteins MMP2 and MMP9 were highly expressed in MCF-7/T/C cells (Da), and they were inhibited after Aurora A knockdown (Db). Representative western blots were shown for each experiment. $\beta$-actin was adopted as loading controls.

regulates cell cycle through cyclin $\mathrm{B} / \mathrm{cdc} 2$ in $\mathrm{MCF}-7 / \mathrm{T}$ cells. In addition, knockdown of Aurora A downregulated Bcl-2 and induced the cleavage of caspase- 3 and PARP in MCF-7/T/ AurA1 and MCF-7/T/AurA2 cells, suggesting that knockdown of Aurora A might enhance apoptosis (Fig. 5Cc).

MMPs play an important role in degrading extracellular matrix components and promoting invasion of tumor cells (28). We observed that the expression of MMP2 and MMP9 was much higher in MCF-7/T/C cells than that in the MCF-7/T/ AurA1 and MCF-7/T/AurA2 cells (Fig. 5Da and Db), implying that silencing Aurora A might inhibit the invasion of MCF-7/T cells.

Inhibition of Aurora A restores the sensitivity of $M C F-7 / T / C$ to Taxol in vitro. To investigate the chemosensitivity of MCF-7/T/C cells to Taxol after knockdown of Aurora A, we performed dose-response experiments to measure $\mathrm{IC}_{50}$ values with Taxol treatment for $72 \mathrm{~h}$. As expected, the MCF-7/T/C cells showed lower sensitivity to Taxol $\left(\mathrm{IC}_{50}=85.72 \pm 3.41 \mathrm{nmol} / \mathrm{l}\right)$ than $\mathrm{MCF}-7 / \mathrm{C}$ cells $\left(\mathrm{IC}_{50}=0.43 \pm 0.022 \mathrm{nmol} / \mathrm{l}\right)$ (Fig. 6A). In contrast, inhibition of Aurora A increased the susceptibility of MCF-7/T/C to Taxol, the $\mathrm{IC}_{50}$ values for MCF-7/T/AurA1 and MCF-7/T/AurA2 reduced to $12.67 \pm 0.20$ and $3.25 \pm 0.77 \mathrm{nmol} / \mathrm{l}$, respectively. The sensitivity to Taxol advanced 6.8- and 26.4-fold in MCF-7/T/AurA1 and MCF-7/T/AurA2 cells, respectively, as compared with that in the $\mathrm{MCF}-7 / \mathrm{T} / \mathrm{C}$ cells (Fig. 6A). These results indicated that inhibition of Aurora A resulted in enhanced chemosensitivity in Taxol-resistant breast cancer cells.

Inhibition of Aurora A enhances the Taxol-induced MCF-7/T cell death. The MCF-7/T cells were administered with Taxol for $72 \mathrm{~h}$ and cell death (SubG1) was evaluated after PI staining by FCM. Taxol induced death in a dose-dependent manner. When the cells were treated with $1.0 \mathrm{nmol} / 1$ Taxol, the percentages of death cells in MCF-7/C and Taxol-resistant MCF-7/T/C cells were $42.53 \pm 2.87$ and $7.78 \pm 0.92 \%$, respectively. The percentage of dead MCF-7/T/C cells elevated to $24.83 \pm 3.33 \%$ at a dose of $10.0 \mathrm{nmol} / \mathrm{l}$ of Taxol (Fig. 6B). Whereas, the MCF-7/T/AurA2 knockdown cells presented much higher dead cell percentages after Taxol treatment, $25.57 \pm 2.82 \%$ $(1.0 \mathrm{nmol} / \mathrm{l})$ and $48.03 \pm 2.58 \%(10.0 \mathrm{nmol} / \mathrm{l})$, suggesting that inhibition of Aurora A in MCF-7/T cells could enhance Taxolmediated death.

\section{Discussion}

Taxol resistance is a major obstacle to successful chemotherapy in cancer patients. In our previous study, we detected that $\mathrm{p}$-Aurora A, along with p-gp, was highly expressed in 
A

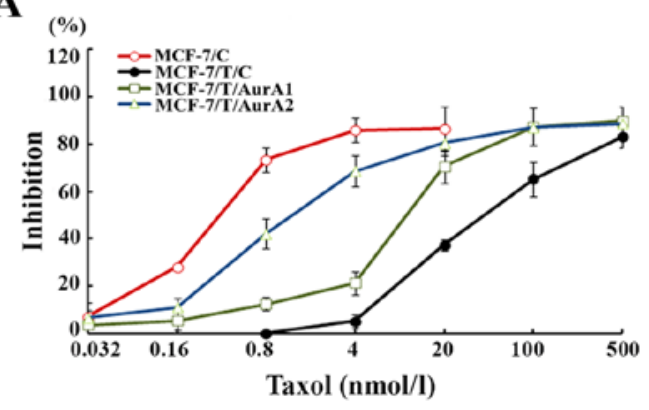

B

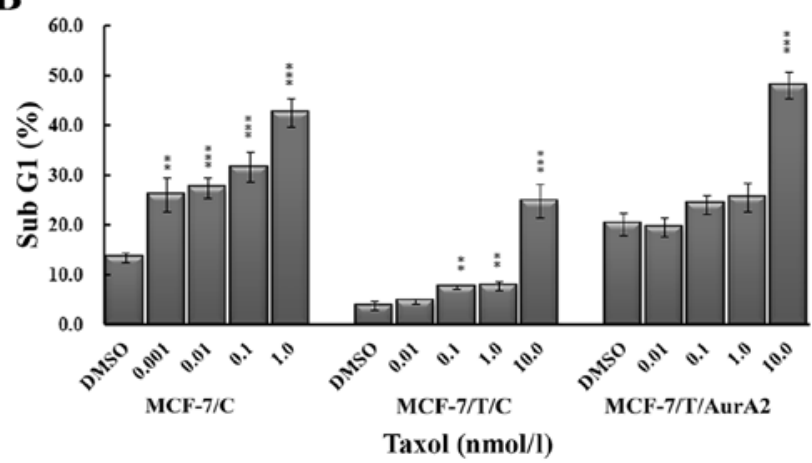

Figure 6. Silencing of Aurora A partially restored the Taxol-sensitivity of MCF-7/T cells in vitro. (A) MCF-7/C, MCF-7/T/C, MCF-7/T/AurA1 and MCF-7/T/ AurA 2 cells were treated with various concentrations of Taxol for $72 \mathrm{~h}$, and proliferation curves of these cells are shown. The Taxol-sensitivity of the silenced MCF-7/T/AurA1 and MCF-7/T/AurA2 cells was increased compared to the control cells. Cell viability was determined using the CCK-8 assay. The viability of the untreated cells was regarded as $100 \%$. The points are the means of three independent experiments; bars are SD. (B) MCF-7/C, MCF-7/T/C, MCF-7/T/ AurA 2 cells were treated with various concentrations of Taxol for $72 \mathrm{~h}$. MCF-7/T/AurA2 displayed higher sensitive to Taxol than MCF-7/T/C cells. Dead cells were PI-positive as determined by FCM. Quantification of the PI staining data was determined through the percentages of the cell distribution. The error bars represent standard deviation. ${ }^{* *} \mathrm{P}<0.01 ;{ }^{* * *} \mathrm{P}<0.001$ (compared with DMSO control).

MX-1/T and MCF-7/T cells, and demonstrated that kinase Aurora A was related with tumor resistance in Taxol resistance MX-1/T partly through p-ERK/P-gp (10). However, that study focused on the three triple-negative breast cancer cells, and the mechanism of drug-resistance was only involved in the P-gp and p-ERK. As is known, besides p-gp, Taxol resistance might be attributed to the upregulation of several factors including the Class III $\beta$-tubulin (TUBB3) in lung cancer $(19,29)$, $\mathrm{PI} 3 \mathrm{~K} / \mathrm{Akt} / \mathrm{mTOR}$ (30-33) in breast and renal tumors, NF- $\kappa \mathrm{B}$, FGFR2 and CHK2 (34) in gastric neoplasia $(35,36)$ and SRC in ovarian carcinomas $(16,37)$. In addition, overexpression of Aurora A has been identified in the chemo-resistant breast and ovarian cancer cells $(8,38)$. Thus, we want to further elicit the function of Aurora A in Taxol-resistant ER-positive breast cancer, and investigate the mechanism of resistance related with Aurora A except p-gp.

In this study, we demonstrated that overexpressed Aurora A was associated with the proliferation, invasion, and Taxolresistance of the breast cancer cell line $\mathrm{MCF}-7 / \mathrm{T}$ in vitro and in vivo. Although both Aurora A and p-Aurora A may play a role in the chemoresistance of MCF-7/T cells, p-Aurora A is the dominate factor because the pathway is supposed to be activated through phosphorylation of Aurora A, and phosphorylated Aurora A plays a more active role. Knockdown of the Aurora A concomitantly decreases the p-Aurora A in the same cell. In this study, silencing of Aurora A by microRNA could efficiently inhibit MCF-7/T growth, colony formation, and invasion. The knockdown of the Aurora A led to a significant accumulation of G2/M phase cells and death in vitro, which further confirmed that Aurora A played an important part in the Taxol-resistance of breast cancer cells. In addition, inhibition of Aurora A significantly enhanced the chemosensitivity of the resistant breast cancer cells to Taxol by increasing cell death. These results further elucidated that Aurora A contributed to the Taxol-resistance of breast cancer cells.

Although it has been established that Taxol inhibits cell survival and growth by downregulating Ras/ERK and Akt kinase pathway (11-13), several studies have demonstrated that the Ras/ERK and Akt pathways were overexpressed in drug-resistant ovarian and colorectal cancers $(14,15)$, and the overexpression of Akt and Ras/Raf/ERK pathways might be related to the phosphorylation of SRC (16). Following these previous findings, we performed similar experiments and found that Aurora A, along with SRC, Ras/Raf/ERK and Akt pathway, was highly upregulated in the Taxol-resistant breast cancer cells and xenograft models. Silencing of Aurora A significantly reduced SRC phosphorylation and downregulated the Ras/Raf/ERK and Akt pathway in the Taxol-resistant MCF-7/T cells. Studies indicated that inhibition of SRC tyrosine kinase could enhance the chemosensitivity to Taxol through downregulating several pathways such as Ras/Raf/ERK and PI3K/Akt $(39,40)$, thus, re-sensitize resistant ovarian cancer cells to Taxol $(41,42)$. Consistent with reported findings in ovarian cancer cells, our results showed that Aurora A was related to the Taxol-resistance of breast cancer cells through $\mathrm{SRC}$, and these pathways might regulate the chemoresistance in the Taxol-resistant breast cancer cells. SRC might be a potent molecular target for the therapy of Taxol resistant breast cancer.

In addition, studies have revealed that the growth inhibition was more effective by blocking both Ras/Raf/ERK and $\mathrm{PI} 3 \mathrm{~K} / \mathrm{Akt} / \mathrm{mTOR}$ pathways simultaneously, which reduced Taxol resistance in several types of cancer $(25,26,43)$. Likewise, Taxol-resistant MCF-7/T cells displayed simultaneous activation of SRC, Akt and ERK accompanied with high expression of Aurora A. Silencing Aurora A expression in MCF-7/T cells using microRNA targeting Aurora A led to the decrease of p-SRC Tyr416. Moreover, the silenced MCF-7/T cells showed not only significant low level of activated ERK and Akt, but also low malignancy and high sensitivity to Taxol.

Aurora kinase was the main regulator of cell cycle (44), and inhibition of Aurora A could induce G2/M phase cells. Our results showed the percentage of the $\mathrm{G} 2 / \mathrm{M}$ phase in $\mathrm{MCF}-7 / \mathrm{T}$ cells significantly increased after silencing Aurora A. It has been proposed that inhibition of Aurora A could increase cleavage of procaspase- 3 and reduce Bcl-2 expression through inhibition of Akt (45). Similarly, we observed that the cleaved caspase-3 and PARP proteins significantly increased while 
Bcl-2 and p-Akt decreased in silenced Aurora A MCF-7/T cells. Therefore, we confirmed that silencing of Aurora A led to Akt-related tumor cell growth inhibition and cell death.

In addition, Ras/Raf/ERK and Akt/mTOR pathways have been reported to mediate critical signals for the regulation of MMP secretion and expression $(28,32,46,47)$. In this study, we demonstrated that MMP2 and MMP9 were highly expressed in Taxol-resistant breast cancer cells, and inhibition of Aurora A caused the decrease of MMP2 and MMP9, accompanied with the downregulation of ERK and Akt activity.

In summary, our data demonstrated that the activated Aurora A plays a critical role in Akt and ERK-mediated survival in Taxol-resistant human MCF-7 cells through p-SRC. Inhibition of Aurora A could enhance the sensitivity of drug-resistant MCF-7/T cells to Taxol. The findings provided evidence that Aurora A might provide an additional and effective target for small molecule chemotherapeutic intervention in drug-resistant breast cancer. In addition, pathways such as Ras/Raf/ERK and Akt/mTOR have been well-studied and related inhibitors are available $(25,32,33)$, targeting Aurora A and Ras/Raf/ERK, and Akt/mTOR simultaneously may improve the sensitivity of breast cancer cells to Taxol, which could be a promising strategy for the treatment of patients with Taxol-resistant breast cancer. The insights into the mechanisms of Taxol resistance and sensitization would represent a useful basis for further development of strategies to circumvent Taxol-related chemoresistance in breast cancer clinical practice.

\section{Acknowledgements}

The present study was supported by the National Natural Science Foundation of China (Approval no. 81102025) and the CAMS Initiative for Innovative Medicine (Approval no. 2016-12-M-1-008).

\section{References}

1. Schettini F, Giuliano M, De Placido S and Arpino G Nab-paclitaxel for the treatment of triple-negative breast cancer: Rationale, clinical data and future perspectives. Cancer Treat Rev 50: 129-141, 2016.

2. Wan Y, Huang A, Yang Y, Xie G, Chen X, Hu J, Chen X, Yang L, Li J, Chen L, et al: A vector-based short hairpin RNA targeting Aurora A inhibits breast cancer growth. Int J Oncol 36: $1121-1128,2010$.

3. Chen S, Dong Q, Hu S, Cai J, Zhang W, Sun J, Wang T, Xie J, $\mathrm{He} \mathrm{H}$, Xing J, et al: Proteomic analysis of the proteins that are associated with the resistance to paclitaxel in human breast cancer cells. Mol Biosyst 10: 294-303, 2014.

4. Lu J, Tan M, Huang WC, Li P, Guo H, Tseng LM, Su XH, Yang WT, Treekitkarnmongkol W, Andreeff M, et al: Mitotic deregulation by survivin in ErbB2-overexpressing breast cancer cells contributes to Taxol resistance. Clin Cancer Res 15: 1326-1334, 2009.

5. Lai D, Ho KC, Hao Y and Yang X: Taxol resistance in breast cancer cells is mediated by the hippo pathway component TAZ and its downstream transcriptional targets Cyr61 and CTGF. Cancer Res 71: 2728-2738, 2011.

6. Lens SM, Voest EE and Medema RH: Shared and separate functions of polo-like kinases and aurora kinases in cancer. Nat Rev Cancer 10: 825-841, 2010.

7. Mountzios G, Terpos E and Dimopoulos MA: Aurora kinases as targets for cancer therapy. Cancer Treat Rev 34: 175-182, 2008.

8. Zou Z, Yuan Z, Zhang Q, Long Z, Chen J, Tang Z, Zhu Y, Chen S, Xu J, Yan M, et al: Aurora kinase A inhibition-induced autophagy triggers drug resistance in breast cancer cells. Autophagy 8 : $1798-1810,2012$.
9. Terakawa T, Miyake H, Kumano M and Fujisawa M: Growth inhibition and enhanced chemosensitivity induced by downregulation of Aurora-A in human renal cell carcinoma Caki-2 cells using short hairpin RNA. Oncol Lett 2: 713-717, 2011.

10. Li Y, Tang K, Zhang H, Zhang Y, Zhou W and Chen X: Function of Aurora kinase A in Taxol-resistant breast cancer and its correlation with P-gp. Mol Med Rep 4: 739-746, 2011.

11. Bergstralh DT, Taxman DJ, Chou TC, Danishefsky SJ and Ting JP: A comparison of signaling activities induced by Taxol and desoxyepothilone B. J Chemother 16: 563-576, 2004.

12. Li W, Liu J, Jackson K, Shi R and Zhao Y: Sensitizing the therapeutic efficacy of taxol with shikonin in human breast cancer cells. PLoS One 9: e94079, 2014.

13. Zhang Q, Si S, Schoen S, Chen J, Jin XB and Wu G: Suppression of autophagy enhances preferential toxicity of paclitaxel to folliculin-deficient renal cancer cells. J Exp Clin Cancer Res 32: 99, 2013.

14. Wang NN, Zhao LJ, Wu LN, He MF, Qu JW, Zhao YB, Zhao WZ, Li JS and Wang JH: Mechanistic analysis of taxol-induced multidrug resistance in an ovarian cancer cell line. Asian Pac J Cancer Prev 14: 4983-4988, 2013.

15. Xu R, Nakano K, Iwasaki H, Kumagai M, Wakabayashi R, Yamasaki A, Suzuki H, Mibu R, Onishi H and Katano M: Dual blockade of phosphatidylinositol 3'-kinase and mitogen-activated protein kinase pathways overcomes paclitaxel-resistance in colorectal cancer. Cancer Lett 306: 151-160, 2011.

16. Le XF and Bast RC Jr: Src family kinases and paclitaxel sensitivity. Cancer Biol Ther 12: 260-269, 2011.

17. Liao CH, Sang S, Ho CT and Lin JK: Garcinol modulates tyrosine phosphorylation of FAK and subsequently induces apoptosis through down-regulation of Src, ERK, and Akt survival signaling in human colon cancer cells. J Cell Biochem 96: 155-169, 2005.

18. Qin B, Ariyama H, Baba E, Tanaka R, Kusaba H, Harada M and Nakano S: Activated Src and Ras induce gefitinib resistance by activation of signaling pathways downstream of epidermal growth factor receptor in human gallbladder adenocarcinoma cells. Cancer Chemother Pharmacol 58: 577-584, 2006.

19. Gan PP, Pasquier E and Kavallaris M: Class III beta-tubulin mediates sensitivity to chemotherapeutic drugs in non small cell lung cancer. Cancer Res 67: 9356-9363, 2007.

20. Li Y, Tang K, Zhang L, Li C, Niu F, Zhou W, Yang H, Feng Z and Chen X: The molecular mechanisms of a novel multi-kinase inhibitor ZLJ33 in suppressing pancreatic cancer growth. Cancer Lett 356: 392-403, 2015.

21. Li Y, Zhou W, Wei L, Jin J, Tang K, Li C, Teh BT and Chen X: The effect of Aurora kinases on cell proliferation, cell cycle regulation and metastasis in renal cell carcinoma. Int J Oncol 41: 2139-2149, 2012.

22. Li Y, Zhang ZF, Chen J, Huang D, Ding Y, Tan MH, Qian CN, Resau JH, Kim H and Teh BT: VX680/MK-0457, a potent and selective Aurora kinase inhibitor, targets both tumor and endothelial cells in clear cell renal cell carcinoma. Am J Transl Res 2: 296-308, 2010.

23. Do TV, Xiao F, Bickel LE, Klein-Szanto AJ, Pathak HB, Hua X, Howe C, O'Brien SW, Maglaty M, Ecsedy JA, et al: Aurora kinase A mediates epithelial ovarian cancer cell migration and adhesion. Oncogene 33: 539-549, 2014.

24. Mendiola M, Barriuso J, Mariño-Enríquez A, Redondo A, Domínguez-Cáceres A,Hernández-Cortés G, Pérez-Fernández E, Sánchez-Navarro I, Vara JA, Suárez A, et al: Aurora kinases as prognostic biomarkers in ovarian carcinoma. Hum Pathol 40: 631-638, 2009.

25. Kawaguchi W, Itamochi H, Kigawa J, Kanamori Y, Oishi T, Shimada M, Sato S, Shimogai R, Sato S and Terakawa N: Simultaneous inhibition of the mitogen-activated protein kinase kinase and phosphatidylinositol 3'-kinase pathways enhances sensitivity to paclitaxel in ovarian carcinoma. Cancer Sci 98: 2002-2008, 2007.

26. Knuefermann C, Lu Y, Liu B, Jin W, Liang K, Wu L, Schmidt M, Mills GB, Mendelsohn J and Fan Z: HER2/PI-3K/Akt activation leads to a multidrug resistance in human breast adenocarcinoma cells. Oncogene 22: 3205-3212, 2003.

27. Li JP, Yang YX, Liu QL, Pan ST, He ZX, Zhang X, Yang T, Chen XW, Wang D, Qiu JX, et al: The investigational Aurora kinase A inhibitor alisertib (MLN8237) induces cell cycle G2/M arrest, apoptosis, and autophagy via p38 MAPK and Akt/mTOR signaling pathways in human breast cancer cells. Drug Des Devel Ther 9: 1627-1652, 2015. 
28. Wang X, Lu N, Niu B, Chen X, Xie J and Cheng N: Overexpression of Aurora-A enhances invasion and matrix metalloproteinase-2 expression in esophageal squamous cell carcinoma cells. Mol Cancer Res 10: 588-596, 2012.

29. Gan PP, McCarroll JA, Po'uha ST, Kamath K, Jordan MA and Kavallaris M: Microtubule dynamics, mitotic arrest, and apoptosis: Drug-induced differential effects of betaIII-tubulin. Mol Cancer Ther 9: 1339-1348, 2010.

30. Almhanna K, Cubitt CL, Zhang S, Kazim S, Husain K, Sullivan D, Sebti S and Malafa M: MK-2206, an Akt inhibitor, enhances carboplatinum/paclitaxel efficacy in gastric cancer cell lines. Cancer Biol Ther 14: 932-936, 2013.

31. Clark AS, West K, Streicher S and Dennis PA: Constitutive and inducible Akt activity promotes resistance to chemotherapy, trastuzumab, or tamoxifen in breast cancer cells. Mol Cancer Ther 1: 707-717, 2002.

32. Chen J, Huang D, Rubera I, Futami K, Wang P, Zickert P, Khoo SK, Dykema K, Zhao P, Petillo D, et al: Disruption of tubular Flcn expression as a mouse model for renal tumor induction. Kidney Int 88: 1057-1069, 2015.

33. Wu M, Si S, Li Y, Schoen S, Xiao GQ, Li X, Teh BT, Wu G and Chen J: Flcn-deficient renal cells are tumorigenic and sensitive to mTOR suppression. Oncotarget 6: 32761-32773, 2015.

34. Gutiérrez-González A, Belda-Iniesta C, Bargiela-Iparraguirre J, Dominguez G, García Alfonso P, Perona R and Sanchez-Perez I: Targeting Chk2 improves gastric cancer chemotherapy by impairing DNA damage repair. Apoptosis 18: 347-360, 2013.

35. Haruki K, Shiba H, Fujiwara Y, Furukawa K, Iwase R, Uwagawa T, Misawa T, Ohashi T and Yanaga K: Inhibition of nuclear factor- $\kappa \mathrm{B}$ enhances the antitumor effect of paclitaxel against gastric cancer with peritoneal dissemination in mice. Dig Dis Sci 58: 123-131, 2013.

36. Qiu H, Yashiro M,Zhang X, Miwa A and Hirakawa K: A FGFR2 inhibitor, Ki23057, enhances the chemosensitivity of drugresistant gastric cancer cells. Cancer Lett 307: 47-52, 2011.

37. George JA, Chen T and Taylor CC: SRC tyrosine kinase and multidrug resistance protein-1 inhibitions act independently but cooperatively to restore paclitaxel sensitivity to paclitaxelresistant ovarian cancer cells. Cancer Res 65: 10381-10388, 2005.
38. Ding YH, Zhou ZW, Ha CF, Zhang XY, Pan ST, He ZX, Edelman JL, Wang D, Yang YX, Zhang X, et al: Alisertib, an Aurora kinase A inhibitor, induces apoptosis and autophagy but inhibits epithelial to mesenchymal transition in human epithelial ovarian cancer cells. Drug Des Devel Ther 9: 425-464, 2015.

39. Puls LN, Eadens M and Messersmith W: Current status of SRC inhibitors in solid tumor malignancies. Oncologist 16: 566-578, 2011.

40. Wheeler DL, Iida M and Dunn EF: The role of Src in solid tumors. Oncologist 14: 667-678, 2009.

41. Pengetnze Y, Steed M, Roby KF, Terranova PF and Taylor CC: Src tyrosine kinase promotes survival and resistance to chemotherapeutics in a mouse ovarian cancer cell line. Biochem Biophys Res Commun 309: 377-383, 2003.

42. Chen T, Pengetnze Y and Taylor CC: Src inhibition enhances paclitaxel cytotoxicity in ovarian cancer cells by caspase-9-independent activation of caspase-3. Mol Cancer Ther 4: 217-224, 2005.

43. Kim SH, Juhnn YS and Song YS: Akt involvement in paclitaxel chemoresistance of human ovarian cancer cells. Ann N Y Acad Sci 1095: 82-89, 2007.

44. Fu J, Bian M, Jiang Q and Zhang C: Roles of Aurora kinases in mitosis and tumorigenesis. Mol Cancer Res 5: 1-10, 2007.

45. Long M, Yin G, Liu L, Lin F, Wang X, Ren J, Wei J, Dong K and Zhang $\mathrm{H}$ : Adenovirus-mediated Aurora A shRNA driven by stathmin promoter suppressed tumor growth and enhanced paclitaxel chemotherapy sensitivity in human breast carcinoma cells. Cancer Gene Ther 19: 271-281, 2012.

46. Marshall CJ: MAP kinase kinase kinase, MAP kinase kinase and MAP kinase. Curr Opin Genet Dev 4: 82-89, 1994.

47. Tseng YS, Lee JC, Huang CY and Liu HS: Aurora-A overexpression enhances cell-aggregation of Ha-ras transformants through the MEK/ERK signaling pathway. BMC Cancer 9: 435, 2009. 